\title{
Perancangan Aplikasi Inventori Pada PT Securindo Packatama Indonesia Berbasis JAVA
}

\author{
Agustin Karlina, Tony Sugiarso \\ Program Studi IImu Komputer \\ Fakultas Teknologi Informasi, Universitas Respati Indonesia \\ agustinkarlina1708@gmail.com,tony.sugiarso@urindo.ac.id
}

\begin{abstract}
ABSTRAK
Dalam perusahaan biasanya mempunyai sistem informasi management inventaris untuk mempermudah proses pencatatan barang, pemasukan barang dan pengeluaran barang. Selain itu sistem informasi inventaris akan meminimalisir human error, mempersingkat waktu untuk melakukan pendataan dan mencari data serta dalam hal pembuatan laporan menjadi otomatis. PT. Securindo Packatama Indonesia memiliki Divisi Inventory yang memfasilitasi pegawai dalam kebutuhan sarana dan prasarana yang berkaitan dengan barang operasional perusahaan. Selanjutnya pegawai harus mengisi formulir permintaan barang yang masih menggunakan cara konvensional. Setelah itu, pegawai dapat menerima barang yang di butuhkan. Oleh karena itu untuk mempermudah proses dalam pelaksanaan pemasukan barang maupun pengeluaran barang dibutuhkan sarana berupa aplikasi yang akan dirancang menggunakan PHP dan Mysql yaitu aplikasi inventori barang pada PT. Securindo Packatama indonesia. Dengan adanya aplikasi tersebut diharapkan pengelolaan input barang lebih terkomputerisasi, tidak memakan tempat penyimpanan yang banyak, dan memudahkan proses Selain itu juga bagi pegawai yang ingin melakukan perminataan barang dapat mengisi form terlebih dahulu untuk request barang tanpa perlu datang langsung ke bagian divisi inventory.
\end{abstract}

Kata Kunci : Perancangan, Aplikasi, Inventori, terkomputerisasi

\begin{abstract}
In companies usually have an inventory management information system to facilitate the process of recording goods, entering goods and releasing goods. In addition, the inventory information system will minimize human errors, shorten the time for collecting data and searching for data and in terms of making reports automatically. PT. Securindo Packatama Indonesia has an Inventory Division that facilitates employees in the needs of facilities and infrastructure related to the company's operational goods. Furthermore, the employee must fill out a request for goods which is still using the conventional method. After that, employees can receive the items they need. Therefore, to simplify the process of carrying out the entry of goods and expenditure of goods, a facility in the form of an application that will be designed using PHP and Mysql is needed, namely an inventory application at PT. Securindo Packatama Indonesia. With this application, it is hoped that the management of input goods is more computerized, does not take up a lot of storage space, and facilitates the process. In addition, employees who want to request goods can fill out the form first to request goods without the need to come directly to the inventory division.
\end{abstract}


Keywords: Design, Application, Inventory, computerized

\section{PENDAHULUAN}

PT. Securindo Packatama Indonesia telah melayani negeri ini sejak tahun 1992 dan telah memiliki banyak cabang kurang lebih 900 lokasi, beberapa kota terbesar di Indonesia yakni Jabodetabek, Bandung, Surabaya, Yogyakarta, Batam, Medan, Manado, Pekanbaru, Padang, Palembang, Makasar, Lampung, Balikpapan, Bali, Semarang, Solo, Jambi, Binjai, dan Gorontolo. Dan memiliki 15.000 tenaga kerja, sehingga data persediaan barang harus terorganisir dengan baik.

Persediaan stok barang pada pusat maupun cabang pada PT. Securindo Packatama Indonesia yang meliputi beberapa inventaris lapangan berupa sperpart Bome gate,rambu-rambu ,tali pita, rante plastic, steak pembatas jalur,kun kerucut, lampu trafik, seragam petugas, rompi lapangan, tinta printer, kamera CCTV, kertas printer, karcis tiket manual, bolpoint, lampu pos (neon).

Pada saat di butuhkan salah satu barang tersebut maka pegawai lapangan harus menanyakan kepada petugas barang apakah barang yang di butuhkan ada ataupun tidak. Selanjutnya petugas barang akan mengecek berupa catatan manual sebelum ke Gudang barang. Dan waktu yang di butuhkan oleh petugas barang apakah barang tersedia

\begin{abstract}
kepada petugas lapangan memerlukan estimasi waktu yang tidak sebentar dikarenakan pencarian data stok barang masih bersifat manual dan berbentuk kertas, dan karena sifat data yang manual bisa saja data tersebut hilang dan terselip dengan data lainnya sehingga membuat estimasi kepastian stok barangb manjadi tidak menentu.
\end{abstract}

\section{METODE}

\section{a. System Development Life Cycle (SDLC)}

Metode penelitian yang digunakan menggunakan System Development Life Cycle (SDLC). SDLC adalah sebuah proses pengembangan software yang digunakan untuk menganalisis sistem, untuk mengembangkan sebuah sistem informasi dengan melalui beberapa tahapan atau langkah-langkah. Metode-metode yang digunakan dalam SDLC pada penelitian ini yaitu mengunakan prototype.

Prototype adalah salah satu metode pengembangan software yang mengijinkan pengguna/user memiliki gambaran awal tentang progam yang akan dikembangkan serta melakukan pengujian awal.

Metode ini menyajikan gambaran lengkap dari suatu sistem perangkat lunak, terdiri atas model kertas, model kerja dan progam . 


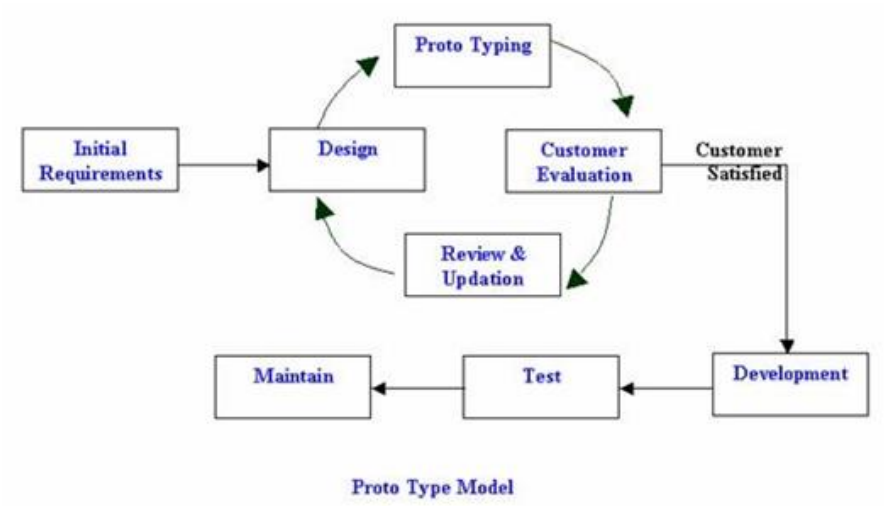

Gambar 1. prototyping by shydestinydeer

Tahapan Prototype

1. Pengumpulan kebutuhan

Pelanggan dan pengembang Bersama-sama mendefinisikan format seluruh perangkat lunak semua kebutuhan, dan garis besar sistem yang akan dibuat.

\section{Membangun Prototyping}

Dengan membuat perancangan sementara yang berfokus pada penyajian kepada pelanggan (Misal membuat input dan format output).

\section{Evaluasi Prototyping}

Evaluasi ini dilakukan oleh pelanggan , jika sudah sesuai maka langkah selanjutnya akan diambil . Namun jika belum sesuai maka prototyping nya direvisi dengan mengulang langkahlangkah sebelumnya.

\section{Mengkodekan Sistem}

Dalam tahap ini prototyping yang sudah disepakati diterjemahkan kedalam bahasa pemograman yang sesuai.

\section{Menguji Sistem}

Setelah sistem menjadi suatu perangkat lunak, kemudian dilakukan proses pengujian .

6. Evaluasi Sistem

Pelanggan akan mengevaluasi apakah perangkat lunak sudah jadi dan sudah sesuai yang diharapkan. Jika Ya maka proses akan dilanjutkan ke tahap selanjutnya. Namun jika Tidak maka mengulang tahap sebelumnya.

\section{Menggunakan Sistem}

Perangkat lunak yang telah diuji dan diterima pelanggan siap untuk digunakan .

\section{b. Pemodelan Sistem}

Pemodelan yang digunakan yaitu dengan Flow Of Document (FOD) dan Data Flow Diagram (DFD) . 


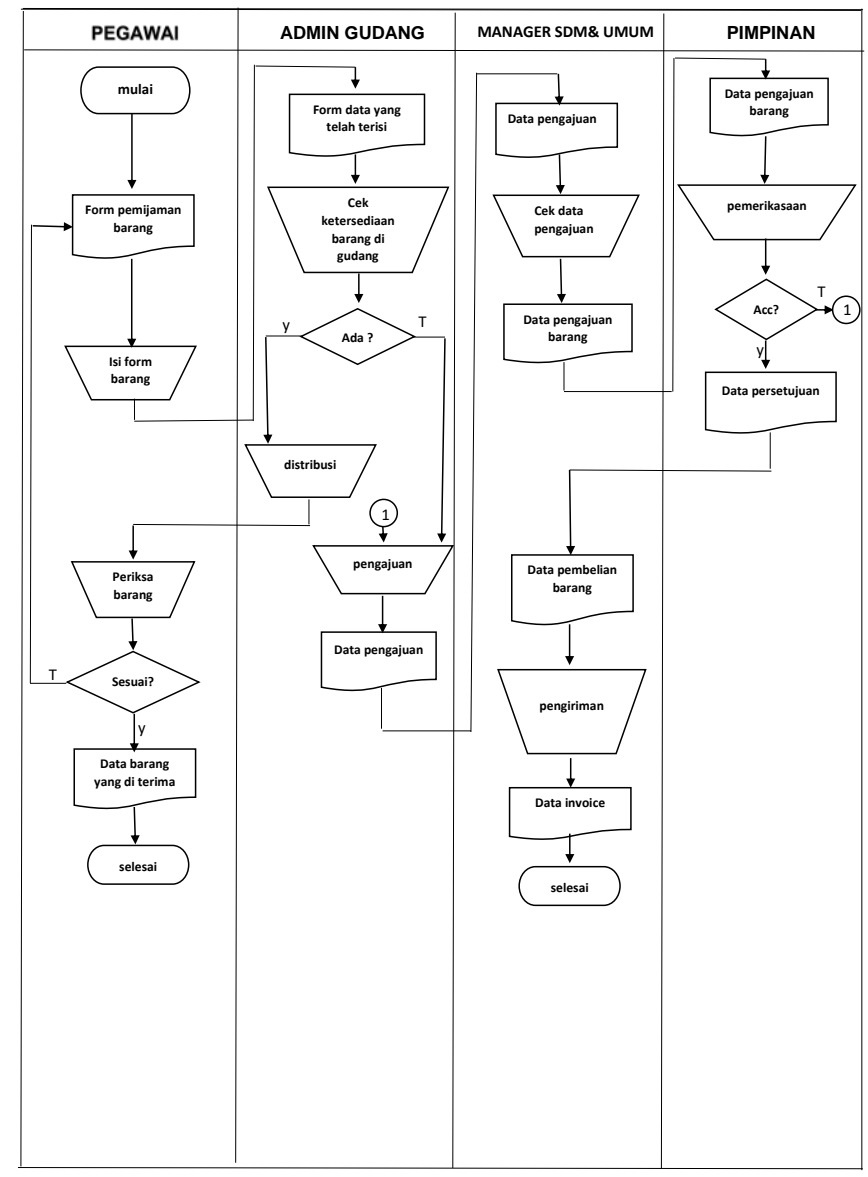

Gambar 2 : FOD Sistem yang sedang berjalan

\section{c. Skema database}

Database

relasional merupakan

jenis Database Management System (DBMS) yang memberikan gambaran atau bagan skema yang menjelaskan tentang hubungan antar tabel bisa dilakuan di dalam sebuah database. 


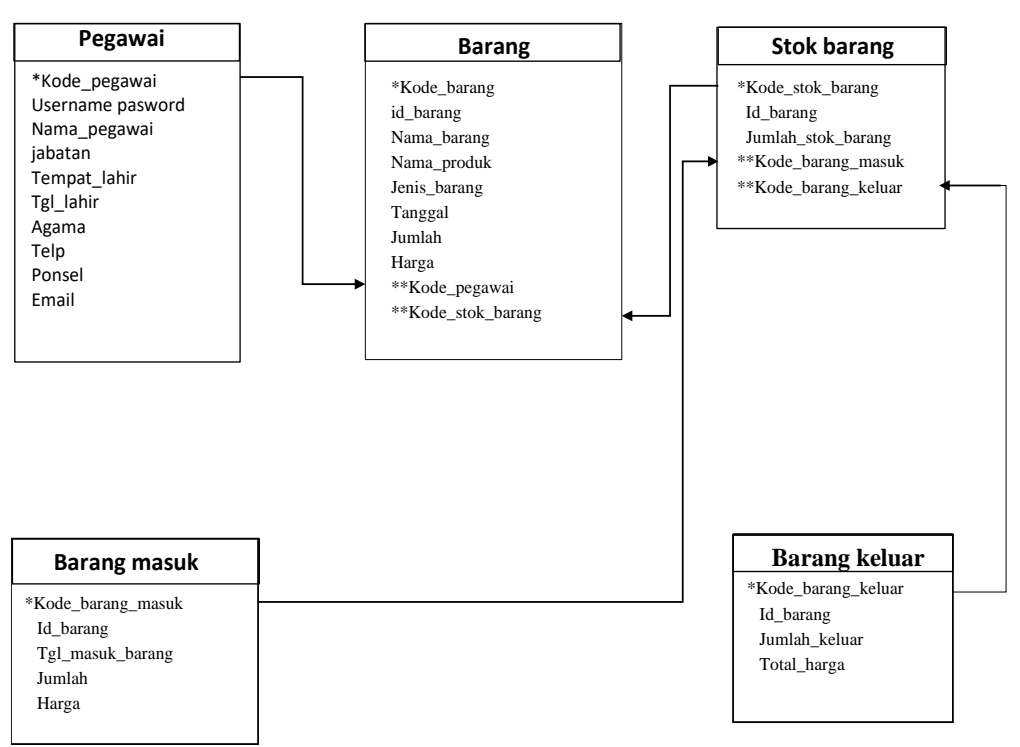

Gambar 3. Skema database 


\section{HASIL DAN PEMBAHASAN}

a. Rancangan User Interface Rancangan

user interface adalah gambaran atau rancangan konseptual dari tampilan layar dan screen format user interface yang akan dirancang baik dari sisi masukan maupun keluaran dari sistem yang akan diusulkan. Berikut adalah tampilan layar pada aplikasi inventori pada PT. securindo packatama indonesia.

1. Rancangan Tampilan Halaman Login

Halaman login adalah rancangan yang dibuat dengan tujuan sebagai halaman autentifikasi admin pada saat mengakses halaman utama admin. Berikut adalah tampilannya.

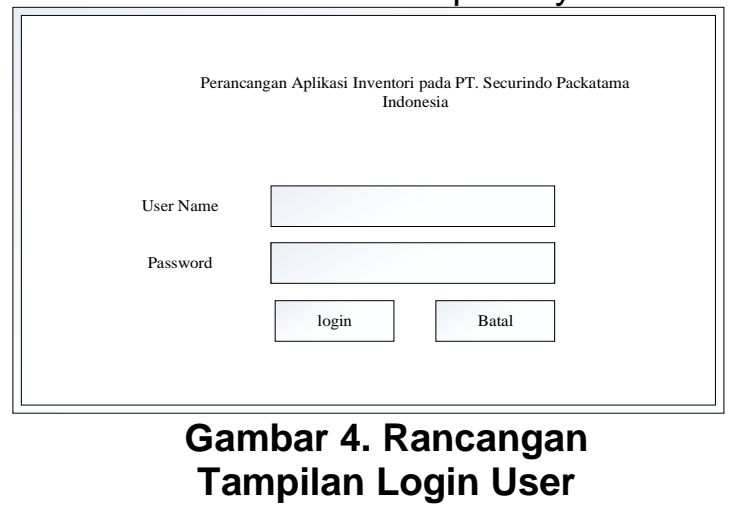

\section{Rancangan Form Data Pemasukan Barang

$\begin{array}{lr}\text { Berikut adalah tampilan } \\ \text { perancangan form } & \text { Data } \\ \text { Pemasukan Barang } & \end{array}$

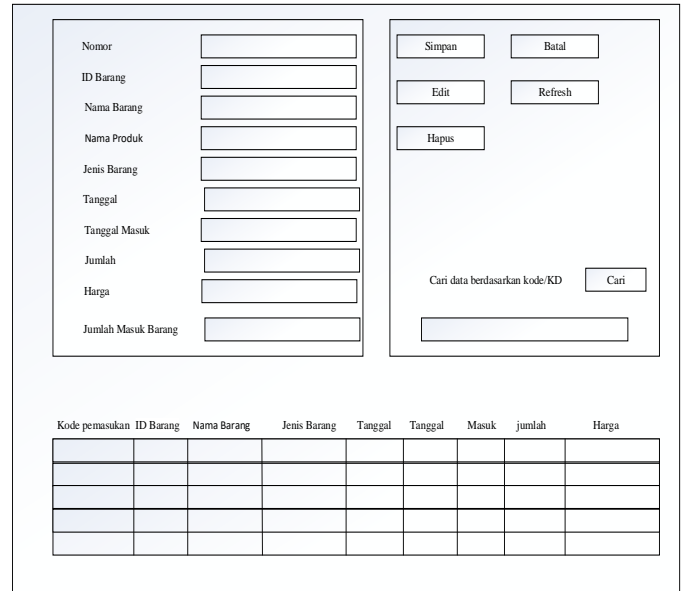

Gambar 5. Rancangan Tampilan form Data Barang Masuk

\section{Rancangan Form \\ Pengeluaran Barang}

Berikut adalah tampilan perancangan form Data Pengeluaran Barang

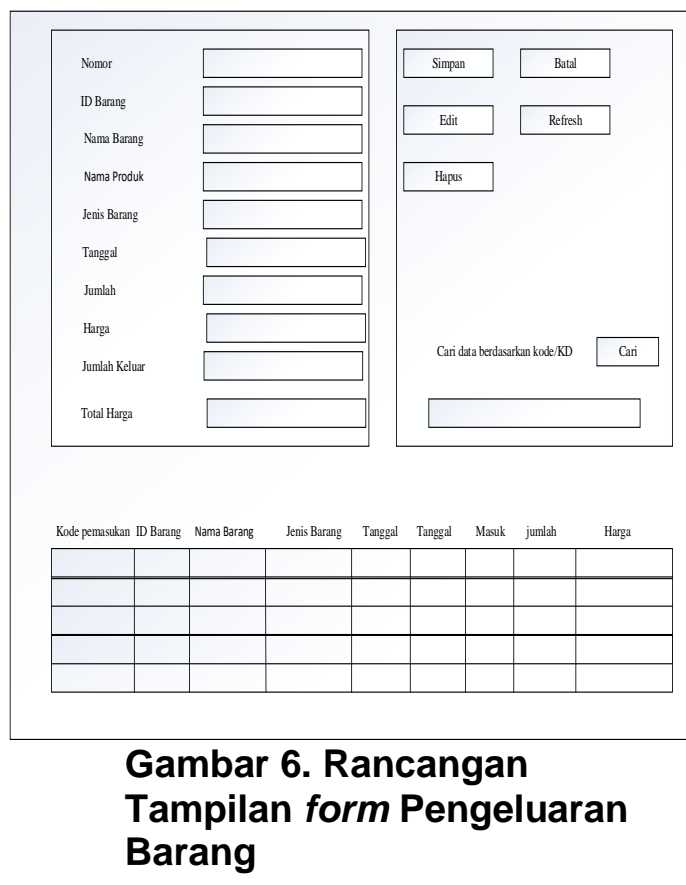

Rancangan Form Stok
Barang 
Berikut adalah tampilan perancangan form Stok Barang

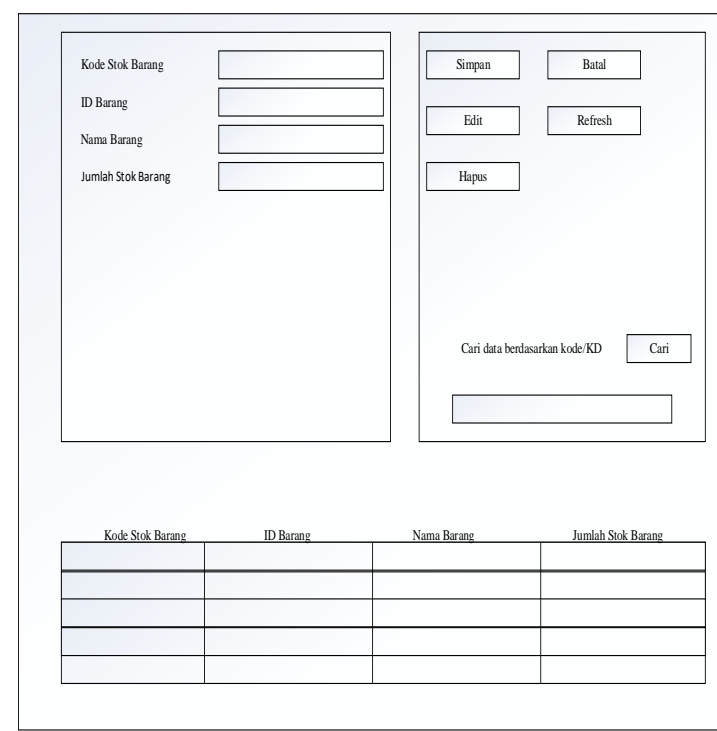

Gambar 7. Rancangan Tampilan form Stok Barang

\section{b. Rancangan Fisik User Interface}

Rancangan fisik user interface Sistem Perancangan Sistem Inventory adalah sebagai berikut :

\section{Menu Login}

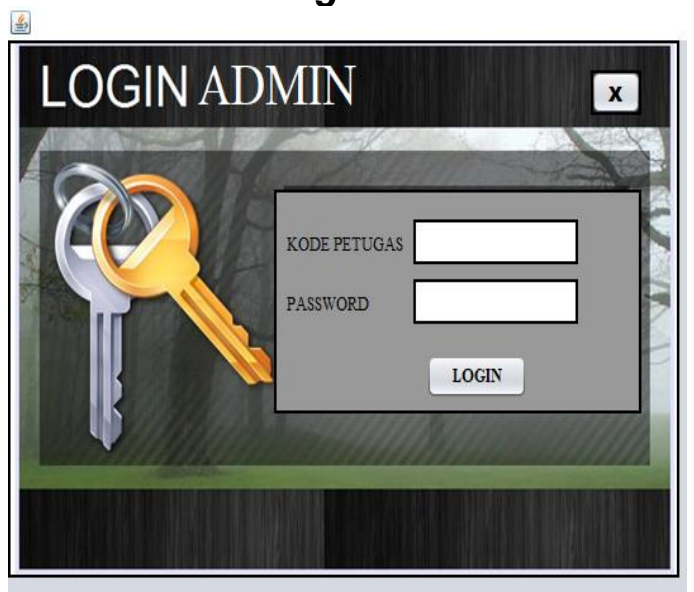

Gambar 8. Tampilan menu Login

Tampilan ini terdapat pada awal program. Menu login digunakan sebagai kata kunci sebelum kita memasuki program utama. Agar tidak sembarang orang dapat mengakses program ini. Sehingga dalam form menu kerahasiaan tetap terjaga dengan baik. Apabila pengguna dapat memasukan nama pengguna dan kata kunci dengan tepat, maka menu utama akan tampil dan program siap untuk dijalankan.

\section{Menu Utama}

Tampilan menu sistem persediaan barang pada PT. Securindo Packatama Indonesia.

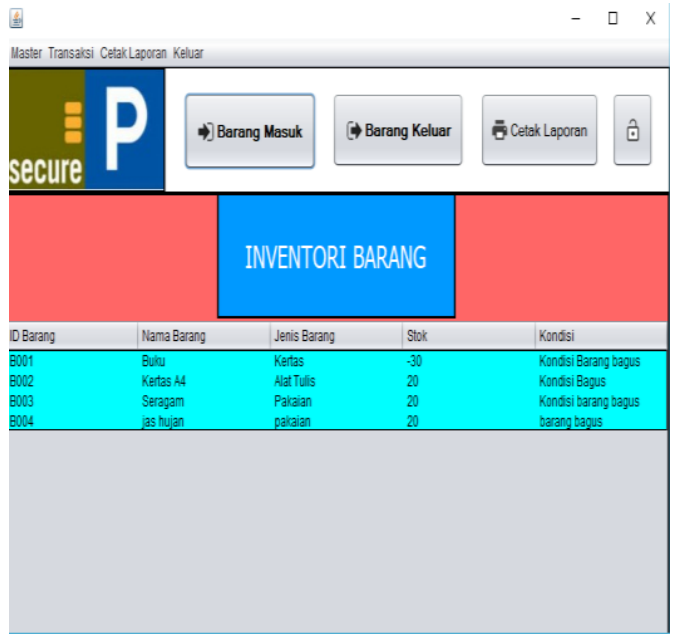

Gambar 9. Tampilan menu utama

\section{Form Data Barang Masuk}

Tampilan form Data Barang masuk yang digunakan untuk menglnput data-data Barang Masuk. Pada form ini terdapat beberapa tombol yang berfungsi untuk menambahkan data yang baru, menyimpan semua kegiatan penglnputan yang terjadi pada menu ini, dan mengeluarkan dari form data barang masuk untuk kembali ke menu utama 


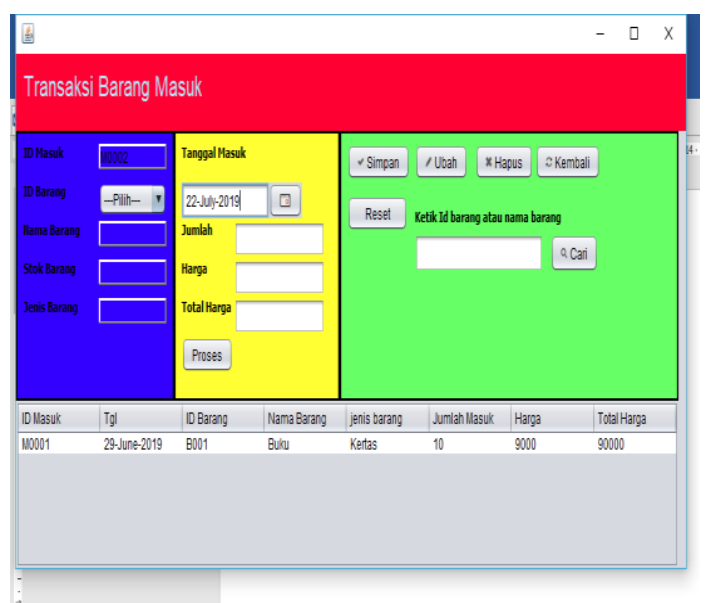

\section{Gambar 10. Tampilan Form Data Barang Masuk}

\section{Form Pengeluaran Barang}

Pada tampilan form Pengeluaran Barang memiliki beberapa tombol yang dapat digunakan untuk menambah, mengubah, membatalkan, dan menghapus semua file pengeluaran barang yang telah di input. Form ini juga memili tombol yang juga digunakan keluar dan kembali ke tampila menu utama

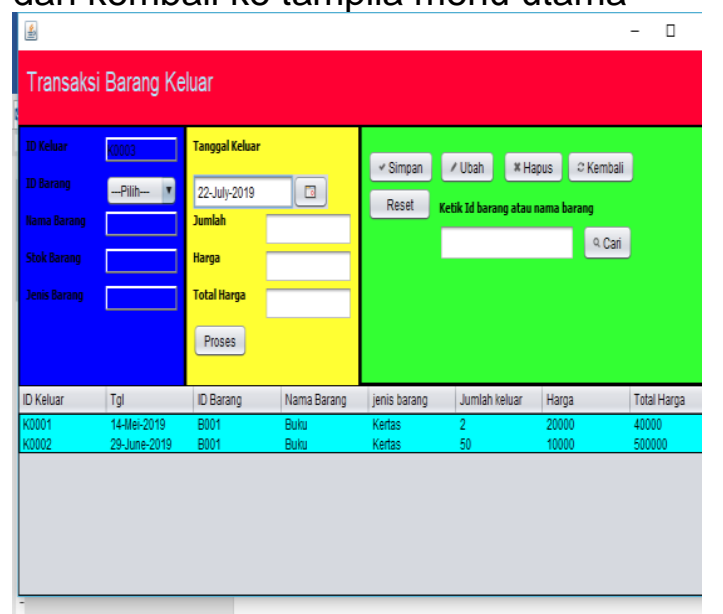

\section{Gambar 11. Tampilan Form Pengeluaran Barang}

\section{Form Data Stok}

From ini digunakan ketika user telah menerima data pemasukan dan data pengeluaran barang dari bagian gudang untuk di input dan di cetak kemudian dilaporakan kepada pimpinan. Setelah itu data hasil tersebut disimpan melalui form ini dengan beberapa tombol yang bisa digunakan. Sedangkan untuk mengembalikan user ke menu utama cukup menekan tombol Menu Utama.

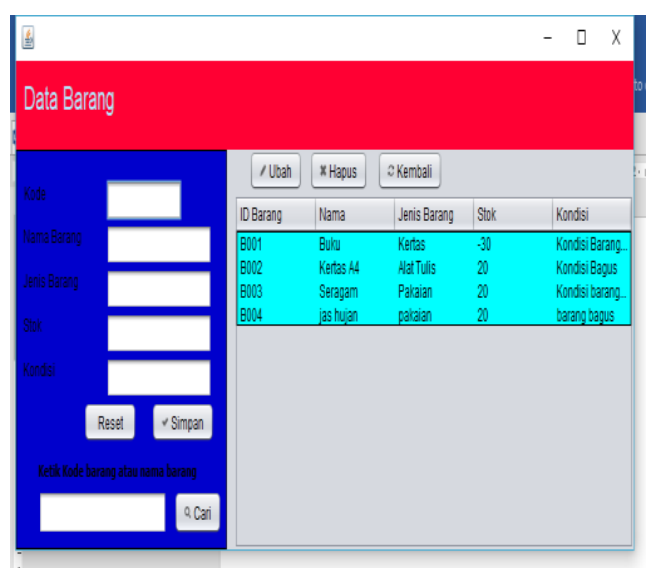

Gambar 12. Tampilan Form Data
Stok

\section{SIMPULAN}

Dengan adanya aplikasi inventori pegawai tidak perlu Datang langsung ke bagian inventory untuk mengisi form peminjaman barang. Aplikasi juga dapat mempercepat proses permintaan kebutuhan barang.

\section{DAFTAR PUSTAKA}

Al Fatta, Hanif. (2011). Analisis dan Perancangan Sistem Informasi. Yogyakarta : Andi Offset.

Arif, Muhammad. (2016). Bahan Ajar Teknik Industri. Yogyakarta : Deepublish.

Hutahaean, Jeperson. (2015). Sistem Informasi Manajemen. Yogyakarta: Graha IImu.

Jogiyanto. (2010). Analisis dan Desain Sistem Informasi, Edisi IV. Yogyakarta: Andi Offset.

J. W. Satzinger, R. B. Jackson and S. D. Burd. (2011). Systems Analysis 
and Design in a Changing World, Sixth ed.

Kadir, Abdul. (2014). Pengenalan Sistem Informasi Edisi Revisi. Yogyakarta : Andi.

Koher, Eric L.A. (2009). Produksi dan Bahan Baku. Jakarta : GRAMEDIA.

Kristanto, Andri. (2011). Perancangan Sistem Informasi dan Aplikasinya. Yogyakarta : Andi.

Martha., Sri Hartati \& Imam Setyawan. (2010). Correlation Among Self-Esteem With $A$ Tendency Hedonist Lifestyle Of Students At Diponegoro University. UNDIP : Undergraduate Thesis.

Murdifin Haming dan Mahfud Nurnajamuddin. (2014). Manajemen Produksi Modern, Operasi Manufaktur dan Jasa, Buku Kesatu. Jakarta : PT. Bumi Aksara.

Rangkuti, Freddy. (2009). Strategi Promosi yang Kreatif dan Analisis Kasus Integrated Marketing Communication. Jakarta : PT. Gramedia Pustaka Utama

Sedarmayanti. (2011). Manajemen Sumber Daya Manusia, Reformasi
Biroaksi dan Manjemen Pegawai Negeri Sipil (cetakan kelima). Bandung : PT. Refika Aditama.

Simonna, Erna. (2009). Definisi Absensi. Yogyakarta : Deepublish.

Sutabri, Tata. (2012). Analisis Sistem Informasi. Yogyakarta: Andi.

Tantra, Rudy. (2012). Manajem Proyek Sistem Informasi. Yogyakarta: Andi Offset. Churcer, Clare. (2007). Database Relasional dengan MySQL, Retrieved April 20, 2016, from : http://www.duniailkom.com/tutorialmysql-pengertian-relationaldatabase/. (08-Mei-2021) http://slamettriyono.blogspot.co.id/2011/02/ pengertian-perancangan.html.

(11-Mei-2021)

http://fahrunit.blogspot.com/2013/05/penge rtian-netbeans.html

(20-Mei-2021)

https://medium.com/@ersandibillah0 3/sdlc-protoype-8a3323c1ca33 (28-Nov-21) 